\title{
The interplay between homogeneous and heterogeneous phases of PdAu catalysts for the oxidation of alcohols
}$$
\text { J. Jover, }{ }^{a, b *} \text { M. García-Ratés, }{ }^{a} \text { N. López }{ }^{a}
$$ \\ ${ }^{a}$ Institute of Chemical Research of Catalonia, ICIQ, The Barcelona Institute of \\ Science and Technology, Av. Països Catalans, 16, 43007 Tarragona, Spain. \\ ${ }^{\mathrm{b}}$ Departament de Química Inorgànica, Universitat de Barcelona, Av. Diagonal \\ 645, 08028 Barcelona, Spain. \\ *e-mail:jesus.jover@qi.ub.es
}

\begin{abstract}
The relationship between the homogeneous and heterogeneous phases of a catalyst is widely neglected in part due to the inherent differences between the experimental and theoretical techniques employed to study them. It is well known that, under reaction conditions, many homogeneous catalysts deactivate and generate black-metals (i.e. nanoparticles). Simultaneously, heterogeneous catalysts tend to suffer of leaching processes under harsh conditions, which produce the formation of species in the homogeneous phase (i.e. volatile or organometallic species). To unravel the links between these two types of catalytic species we have taken $\mathrm{PdAu}$ catalysts in the oxidation of crotyl alcohol to crotonaldehyde and investigated the reaction process for both homogeneous and heterogeneous phases. We show that the process is possible in both phases and, essentially, contains the same elementary steps. The results indicate that the homogenous catalyst is slightly more active; however, the enhanced stability of the heterogeneous phase provides a better performance under relevant reaction conditions. Both catalytic systems are connected through two simple steps that can be computed: oxidative leaching and deposition. The oxidative leaching of the $\mathrm{PdAu}$ nanoparticles in the presence of dioxygen can produce $\mathrm{Pd}(\mathrm{II})$ monomeric species able to catalyze the alcohol oxidation in homogeneous conditions. After the reaction the reduced $\mathrm{Pd}(0)$ homogeneous catalyst is reabsorbed onto the $\mathrm{PdAu}$ nanoparticles, preventing the aggregation process. The present work shows that the full homogeneous/heterogeneous catalytic cycle can be analyzed in a holistic manner with computational techniques.
\end{abstract}

KEYWORDS: palladium catalysis, alcohol oxidation, homogeneous catalysis, heterogeneous catalysis, nanoparticles, density functional theory 


\section{INTRODUCTION}

The link between homogeneous and heterogeneous catalysts is often very subtle. Unfortunately, the different techniques employed in both fields has prevented crossfertilization and limited the appearance of a unified theory in Catalysis. ${ }^{1}$ In the homogeneous catalysis field, often related to organometallic chemistry, soluble molecular catalysts are employed. These molecular species provide single site reactions that can be easily modulated by fine-tuning of the ancillary ligands. In many cases though, these materials show a limited stability and in long time scales and form small aggregates that can either be suspended in the liquid media or even precipitate. ${ }^{2}$ In turn, in heterogeneous reactions where the reactants and the catalysts are in different phases and the catalyst is a solid, leaching can occur in very reactive environments providing small aggregates that might even be responsible for most of the reactivity. Classically, both the homogeneous and heterogeneous communities work in hermetic compartments and little information has permeated the frontier. ${ }^{3}$ Luckily the interweaving of the two fields is growing steered by theoretical methods ${ }^{4}$ that can be employed with comparable accuracies under different conditions, and by detailed experiments that can identify decomposition/formation of homo or heterogeneous species. 5 In addition, the transferability of the catalytic activity from the bulk to nanoparticles or isolated atoms has been observed, gold chemistry being the paradigm. ${ }^{6}$ Other examples were speciation of different potential catalytic structures (Ru in this case) could play a different role have been presented in the literature. ${ }^{7}$

Pd-Au alloys have constituted a wonderful playground in the study of alloys. The synergistic effect between both metals has been recognized to increase the reactivity in heterogeneous catalysis i.e. providing weaker adsorption of reactants and products and higher selectivities. ${ }^{8} \mathrm{PdAu}$ mixtures are known to present appealing properties for the synthesis of vinylacetate monomer $(\mathrm{VAM})^{9}$ and hydrogen peroxide. ${ }^{10}$ They have been also employed in the selective oxidation of alcohols ${ }^{11}$ and aromatic $\mathrm{C}-\mathrm{H}$ bonds, ${ }^{12}$ and in the hydrogenation of $\mathrm{C}-\mathrm{C}$ double bonds, ${ }^{13}$ to name a few group of examples related to industrial and green processes. Pd-Au alloys can be grown in a number of controlled ways including the use of Au seeds where Pd is deposited on top by different chemical tools. ${ }^{14}$ The control of the Pd ensembles on the Au surface has been found to be crucial in many environments including electrochemical samples, ${ }^{15} \mathrm{CO}$ oxidation, ${ }^{16}$ $\mathrm{H}_{2}$ obtention ${ }^{17}$ and activation ${ }^{18}$ or the elimination of chlorine containing compounds. ${ }^{19}$

Recently it has been demonstrated that $\mathrm{Pd}-\mathrm{Au}$ alloys are active in the selective dehydrogenation of alcohols in water at room temperature, and two different 
mechanisms, homogeneous and heterogeneous, originally called redox and $\beta-\mathrm{H}$ elimination pathways, have been postulated (Scheme 1). ${ }^{11 \mathrm{e}}$

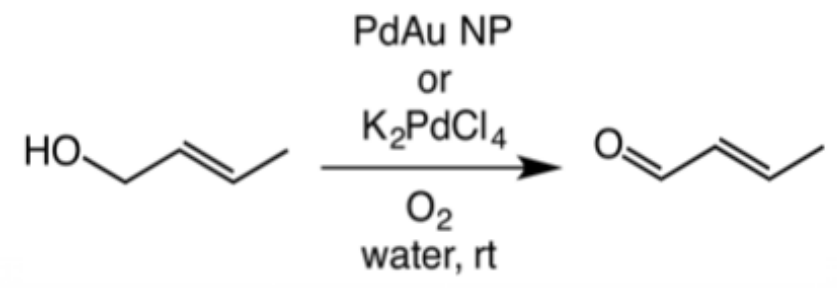

A) Homogeneous (redox)
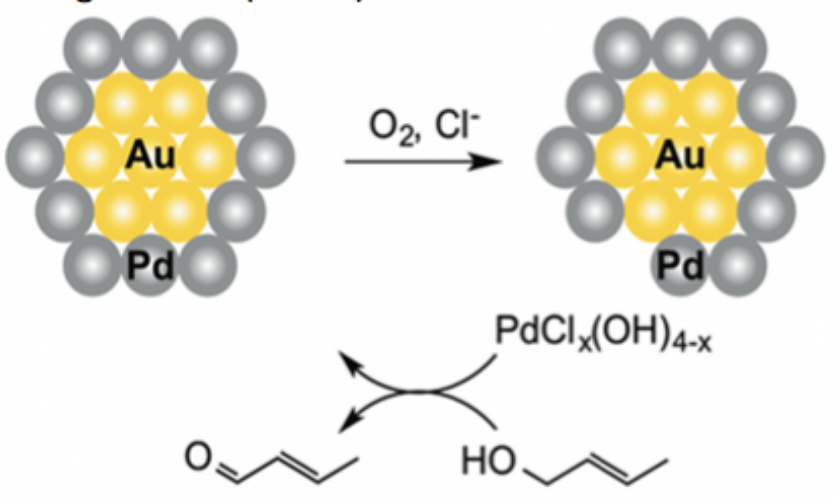

B) Heterogeneous ( $\beta$-H elimination)

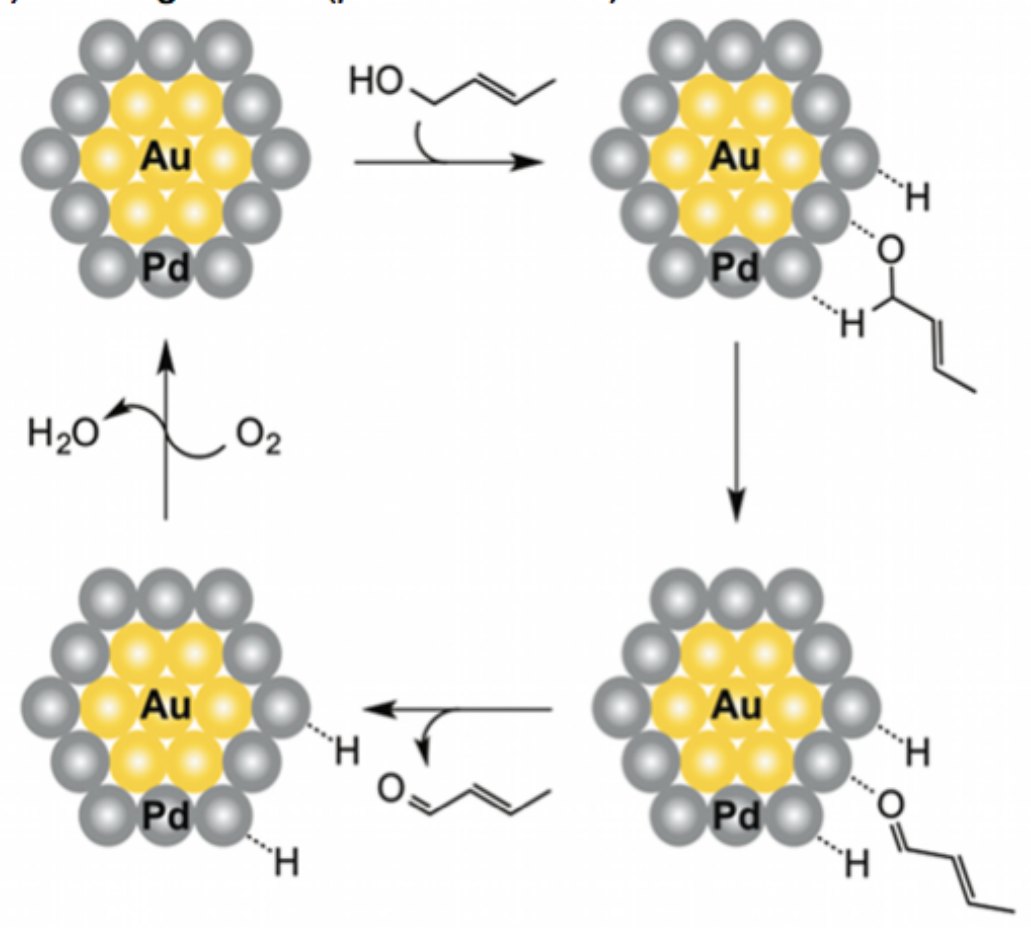

Scheme 1. Plausible reaction pathways for the selective oxidation of crotyl alcohol on homogeneous (A) and heterogeneous (B) phases as proposed in Ref. 10e. "Adapted with permission from (Balcha, T.; Strobl, J.; Fowler, C.; Dash, P.; Scott, R. W. J. ACS Catal. 2011, 1, 425-436.). Copyright 2011 American Chemical Society." 
In the homogeneous case, it has been proposed that the active palladium(II) species $\mathrm{PdCl}_{x}(\mathrm{OH})_{4-x}$ is oxidatively leached from the PdAu nanoparticle with $\mathrm{O}_{2}$ in the presence of chloride. The homogeneous catalyst should then be able to oxidize the crotyl alcohol to the corresponding aldehyde, recovering the initial reduced nanoparticle. A similar mechanism has been recently reported for the formation of vinyl acetate from ethene and acetic acid on PdAu nanoparticles. ${ }^{5 b-d}$ When nanoparticles are not present in the reaction i.e. the starting $\mathrm{Pd}$ species is $\mathrm{K}_{2} \mathrm{PdCl}_{4}$, the aldehyde is still formed but the catalytic activity is much lower. Although palladium(II) catalysts are proposed to be the active species, in these homogeneous reactions it should be expected that a more active $\operatorname{Pd}(0)$ catalyst is present and responsible for the whole process. The reactive species could be obtained by reduction of the starting $\mathrm{Pd}$ (II) salts, either by a reductive elimination process or by an initial reaction where the double bond of the substrate acts as a reductor, as proposed in the literature. ${ }^{20}$ The formation of homogeneous $\operatorname{Pd}(0)$ species could explain why the homogeneous oxidation of crotyl alcohol is sluggish: TOF in 1 hour is $9 \mathrm{~h}^{-1}$ and conversion is lower than $9 \%$. Under the experimental conditions the active $\mathrm{Pd}(0)$ species is probably difficult to obtain and poorly stable since there are not ancillary ligands to prevent the eventual aggregation and formation of palladium black, which kills the reaction, as observed experimentally. This purely homogeneous process should be expected to follow the classical aerobic oxidation/ $\beta$ hydride elimination pathway. ${ }^{21}$

In the heterogeneous case, it has been proposed that the alloy, where Au seeds are (partially) covered by $\mathrm{Pd}$, adsorbs the alcohol and then breaks the $\mathrm{O}-\mathrm{H}$ and the $\mathrm{C}-\mathrm{H}$ (in $\beta$ ) bonds to yield the product. The resulting surface is then cleaned by $\mathrm{O}_{2}$, generating water. In contrast, other studies on similar systems indicate that the mechanism should be closer to the homogeneous version of the reaction. ${ }^{22}$ Therefore, in the studied PdAu system the oxygen dissociation on the catalyst takes place first. The alcohol is then deprotonated by the nascent oxygen atoms on the surface and, after that, the $\beta$ hydrogen migrates to the surface of the nanoparticle. Water is then easily formed and released from the coadsorbed hydrogen and hydroxyl groups. Experimentally it has been observed that the best results are obtained with sequentially reduced core-shell 3:1 PdAu nanoparticles. The TOF with this catalyst is as high as is $306 \mathrm{~h}^{-1}$ in 1 hour and the conversion reaches up to $71 \%$, a much better activity than the one found for the homogenous $\mathrm{K}_{2} \mathrm{PdCl}_{4}$ catalyst. The authors hypothesize that this system shows the best performance because of the near complete coverage of the Au cores by Pd shells and a negligible oxidation of the surface. Subsequent $X$-Ray experiments indicate that these core-shell 3:1 PdAu nanoparticles remain stable in the presence of $\mathrm{O}_{2}$, 
supporting the heterogeneous $\beta$ - $\mathrm{H}$ pathway and ruling out the oxidative leaching process. ${ }^{11 \mathrm{~g}}$

On the other hand, the results obtained from carrying out the oxidation of crotyl alcohol using $\mathrm{Au}$ nanoparticles in the presence of aqueous $\mathrm{K}_{2} \mathrm{PdCl}_{4}$ (in a $1: 3$ ratio) seem to support the homogeneous mechanism. In this case an average activity, better than the $\mathrm{Pd}$ (II) salt alone but worse than the preformed 3:1 PdAu nanoparticles, is found. In this reaction the nanoparticle size significantly increases, pointing to the deposition of $\operatorname{Pd}(0)$ onto the nanoparticle surface. This fact seems to support a homogeneous $\mathrm{Pd}(\mathrm{II})$ mediated mechanism but it can also correspond to the formation of core-shell PdAu nanoparticles that can efficiently catalyze the reaction.

As the reaction takes place under a mixture of homogeneous and heterogeneous conditions the most suited methodology to assess the role of the different potential catalysts in the experiments turns out to be theoretical simulations. This is precisely the aim of the present work. To this end we have employed state-of-the-art theoretical simulations for both the homogeneous and heterogeneous catalysts and analyzed the reaction pathways leading to crotonaldehyde, comparing the reaction networks and the mechanisms that can link both catalyst phases.

\section{COMPUTATIONAL DETAILS}

In order to compare the reaction paths on the homogeneous and heterogeneous phases we have employed Density Functional Theory to model the reaction pathways for both catalytic systems. We have adapted the best computational set-up in each case employing the same functional. The reaction free energies calculated for the overall process in water: $\mathrm{C}_{4} \mathrm{H}_{7} \mathrm{OH}+1 / 2 \mathrm{O}_{2} \rightarrow \mathrm{C}_{4} \mathrm{H}_{6} \mathrm{O}+\mathrm{H}_{2} \mathrm{O}$, differ by around $12 \mathrm{~kJ} \mathrm{~mol}^{-1}$ $\left(-215.0\right.$ and $-227.2 \mathrm{~kJ} \mathrm{~mol}^{-1}$ for the homogeneous and heterogeneous systems, respectively), showing a good agreement between both methodologies. In the case of the heterogeneous system, this reaction energy has been computed including the solvation energies and entropic corrections obtained with the homogeneous model (see below). 


\subsection{Homogeneous reaction path}

All the structures in this pathway have been fully optimized in water (PCM) using the Gaussian09 package, ${ }^{23}$ with the PBE density functional. ${ }^{24}$ The B3LYP ${ }^{25}$ functional was tested for some steps and found to provide similar results as those obtained with PBE (see $\mathrm{SI}$ ). The standard $6-31+\mathrm{G}(\mathrm{d})^{26,27}$ basis set was used for all atoms except for $\mathrm{Pd}$, where the Stuttgart triple zeta basis set (SDD), ${ }^{28}$ along with the associated ECP to describe the 28 core electrons, was employed. Solvation energies are computed with the (IEF-PCM) continuum dielectric solvation model ${ }^{29}$ using the radii and nonelectrostatic terms for Truhlar and coworkers' SMD solvation model. ${ }^{30}$ The Minimum Energy Crossing Point (MECP) between potential energy surfaces with different spin states have been located with the method developed by Harvey and coworkers ${ }^{31}$ using the same basis sets as above. Frequencies were calculated in all cases in order to ensure the nature of local minima and transition states. The relative free energy values are computed at $25^{\circ} \mathrm{C}$. In the case of the MECP the free energy correction was estimated to be equal to that of intermediate II.

\subsection{Heterogeneous reaction path}

The calculations representing the heterogeneous phase of the catalyst were performed considering periodic boundary conditions and plane waves as implemented in the VASP code. ${ }^{32,33}$ The functional of choice was PBE. ${ }^{24}$ The inner electrons were replaced by $\mathrm{PAW}^{32}$ and the valence monoelectronic states were expanded in plane waves with a kinetic cutoff energy of $450 \mathrm{eV}$. The Au bulk was optimized following the standard procedures and then a (111) slab was generated to build the model system is shown in Figure 1. The final structure is a three layers Au slab with a continuous monolayer of $\mathrm{Pd}$ on top epitaxially grown (total of four layers in the slab). To include the Pd the top $\mathrm{Au}$ layer was replaced by $\mathrm{Pd}$ an reoptimized. In all the optimizations the lower two layers of Au were kept to the initial positions thus mimicking the role of the bulk. The surface cell for the adsorption and reactivity studies was a $p(4 \times 6)$ and the slabs were interleaved by more than $10 \AA$. The k-point sampling was performed with $5 \times 2 \times 1 \mathrm{k}$ points with a gamma centered mesh. ${ }^{34}$ The transition state structures where located through the CI-NEB method. ${ }^{35}$ In this case the free energy values at $25^{\circ} \mathrm{C}$ have been approximated by adding the translational entropy to the molecular species, as obtained with the homogeneous methodology. This implies that the energy is shifted up or down whenever an adsorption or desorption step takes place, respectively. The energies of the "aqueous" species i.e. crotyl alcohol, crotonaldehyde, $\mathrm{O}_{2}$ and $\mathrm{H}_{2} \mathrm{O}$ have been 
corrected to include the solvation energies, computed using the homogeneous pathway methodology. In this way, the effect of a species getting onto the solid from the liquid medium (and backwards) is taken into account. We are aware that there are plausible implicit solvation models developed for VASP but those are still under testing. The VASP-MGCM solvation model ${ }^{36}$ was used to calculate the energy for the crotyl alcohol oxidation and a very similar result to the one found in the homogeneous reaction was found: -216.3 and $-215.0 \mathrm{~kJ} \mathrm{~mol}^{-1}$, respectively. However, the application of this solvation model to the $\mathrm{Pd}$ species along the heterogeneous pathway produced uncertain results and thus we decided not to use until it has been successfully tested for species of that kind.

(a)
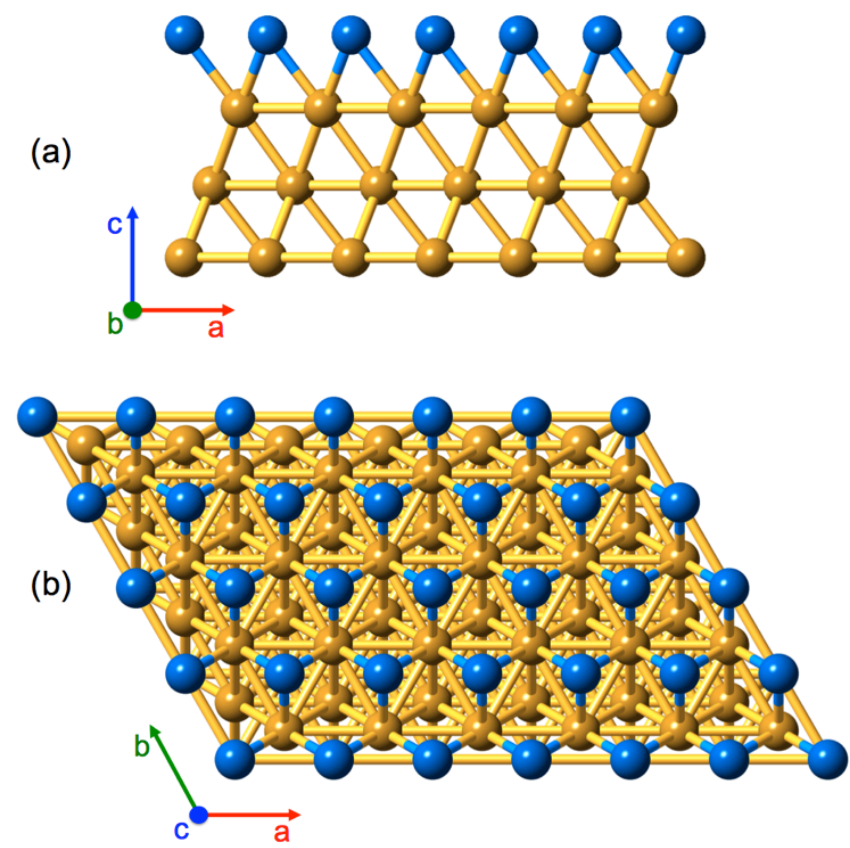

Figure 1. Side (a) and top (b) view of the heterogeneous model $(P d=b l u e, A u=$ yellow). 


\section{RESULTS AND DISCUSSION}

\subsection{Homogeneous phase}

The homogeneous oxidation of crotyl alcohol follows the pathway shown in Scheme 2. The starting catalytic species is the palladium(0) complex $\left[\mathrm{PdCl}_{2}\right]^{2-}(\mathrm{I})$, probably formed by reduction of the starting $\mathrm{K}_{2} \mathrm{PdCl}_{4}$ salt with the double bond of the substrate. I cannot be directly obtained by reductive elimination from $\left[\mathrm{PdCl}_{4}\right]^{2-}$ because the reaction would be highly endergonic; the aerobic oxidation to $\left[\mathrm{PdCl}_{4}\left(\mathrm{O}_{2}\right)\right]^{2-}$ side-on peroxopalladate seems also quite unlikely, although this oxidation process is not as high in energy as the direct reductive elimination.

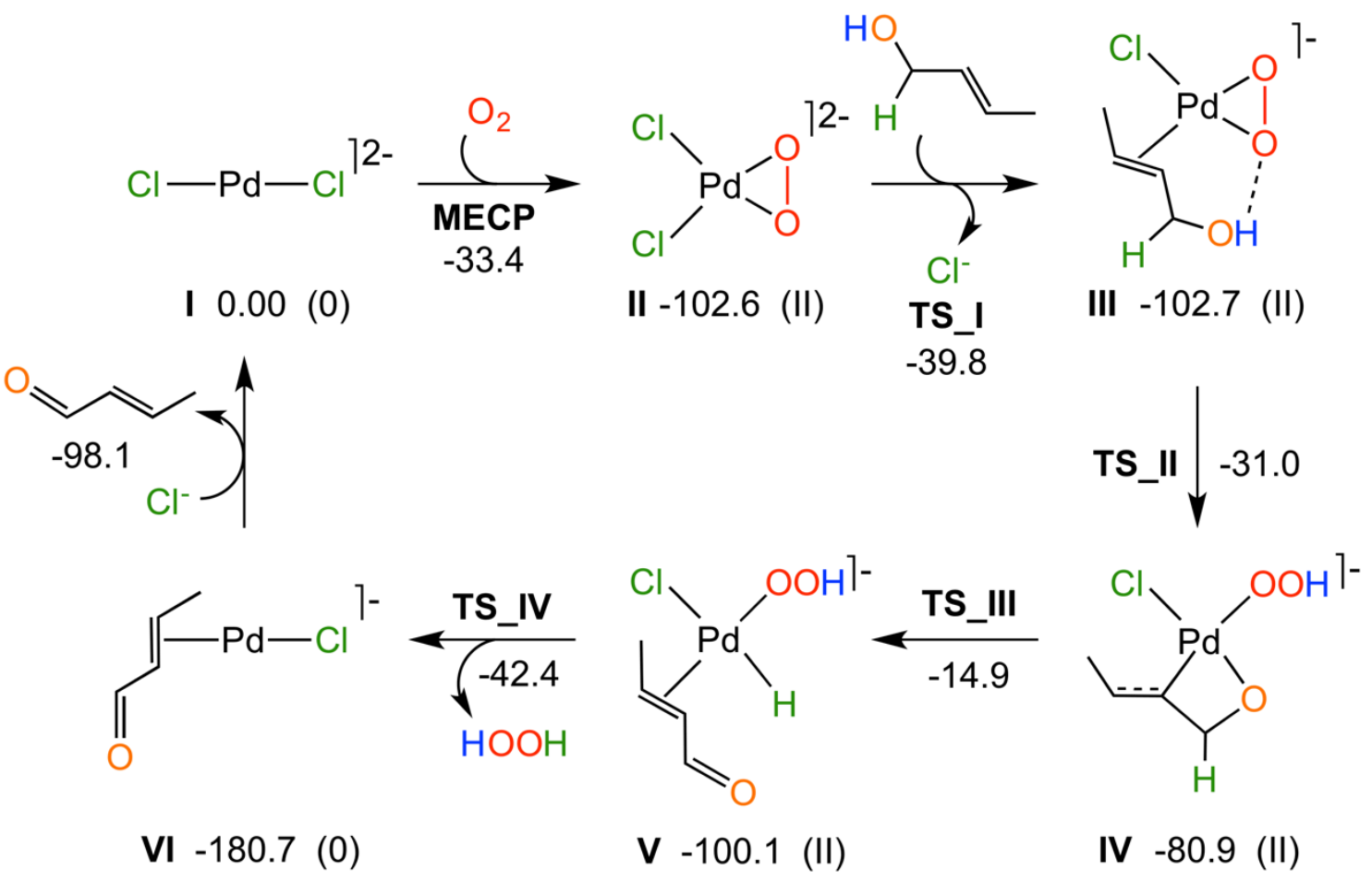

Scheme 2. Mechanism proposed for the homogeneous Pd-catalyzed oxidation of crotyl alcohol (relative free energies in $\mathrm{kJ} \mathrm{mol}^{-1}$, the palladium oxidation state is shown between parenthesis).

The catalytic cycle starts when I reacts with dioxygen to form the side-on palladium(II)peroxo species II. Similar $\operatorname{Pd}(\mathrm{II})$ side-on peroxopalladate intermediates have been reported to be formed in open air palladium(0) reactions and some examples have been crystallized. ${ }^{37}$ The step from I to II is exergonic by $102.6 \mathrm{~kJ} \mathrm{~mol}^{-1}$ and involves a spin-crossing from triplet to singlet through a minimum energy crossing point (MECP). 
This MECP was found to lie at $-33.4 \mathrm{~kJ} \mathrm{~mol}^{-1}$; slightly lower than the separated reactants. Calculations on other similar palladium( 0$)$ systems corroborate that the energy requirement for this transformation is practically non-existent. ${ }^{38}$ Then the crotyl alcohol substrate comes in and replaces one of the chloride ligands to form intermediate III. This process has an associated barrier (TS_I) of $62.8 \mathrm{~kJ} \mathrm{~mol}^{-1}$, low enough to allow the reaction to proceed without any problem. The relative free energy remains practically the same at both sides of this barrier, indicating that the interaction between the metal and the double bond in III is strong enough to push the chloride far away from the palladium. In this complex there is an additional hydrogen bond formed between the alcohol group and one oxygen atom of the side-on peroxide ligand; the $\mathrm{OH}-\mathrm{O}_{2}$ distance is $1.94 \AA$. The reaction proceeds by the proton transfer from the crotyl alcohol to the peroxo group. This step has a relatively low barrier of $71.7 \mathrm{~kJ} \mathrm{~mol}^{-1}$ and produces the four-membered cyclopalladate intermediate IV, which lies a bit higher in energy than III but still well below the deprotonation transition state (TS_II). In IV, an extra hydrogen bond is established between the hydroperoxo and chloride ligands. This particular arrangement favors the $\beta$-hydride elimination on the metal center and delivers intermediate $\mathbf{V}$. The barrier associated to this step, and controlled by the corresponding transition state (TS_III), is $66.0 \mathrm{~kJ} \mathrm{~mol}^{-1}$, which should be easily affordable under the reaction conditions. At this point the final crotonaldehyde product is already formed but remains attached to the palladium. Hydrogen peroxide, the corresponding 2-electron reduction product of $\mathrm{O}_{2}$, is then released through the corresponding reductive elimination transition state (TS_IV); this process is quite straightforward and requires $57.7 \mathrm{~kJ} \mathrm{~mol}^{-1}$. Finally, a chloride ligand replaces the crotonaldehyde onto the palladium( 0 ) intermediate $\mathbf{V I}$ to regenerate the initial catalyst and close the catalytic cycle. This step is endergonic and requires $98.1 \mathrm{~kJ} \mathrm{~mol}^{-1}$ to take place; nevertheless, the associated energy barrier was not found. In contrast, a monotonic uphill energy profile was found in a series of calculations were the incoming chloride and the leaving product were fixed at different distances. Although the energy requirement for this stage seems quite high it can be compensated by the disproportionation of $\mathrm{H}_{2} \mathrm{O}_{2}$ in aqueous media to form one half of $\mathrm{O}_{2}$ and water. This process is exergonic by $116.9 \mathrm{~kJ} \mathrm{~mol}^{-1}$, making the overall reaction energy exergonic by $215.0 \mathrm{~kJ} \mathrm{~mol}^{-1}$. $\mathrm{H}_{2} \mathrm{O}_{2}$ can be also employed as oxidant for the starting species $\mathrm{I}$, thus generating a second catalytic cycle with similar energy requirements to the one shown in Scheme 2 (see SI, Scheme S1).

As stated above, the overall energetics indicates that the reaction is exergonic by 215.0 $\mathrm{kJ} \mathrm{mol}^{-1}$. The highest computed barrier is located between intermediate III and the $\beta$ - 
hydride elimination transition state (TS_III) with an associated energy requirement of $87.8 \mathrm{~kJ} \mathrm{~mol}^{-1}$. The magnitude of the computed barrier shows the reaction should work smoothly under the experimental conditions employed. However, the strong tendency of $\operatorname{Pd}(0)$ species such as I to aggregate and produce palladium black, ${ }^{2}$ seems to explain the observed low TOF and conversion when $\mathrm{K}_{2} \mathrm{PdCl}_{4}$ is used as catalyst.

\subsection{Heterogeneous phase}

The mechanism describing the heterogeneous oxidation of crotyl alcohol by PdAu nanoparticles is shown in Scheme 3.

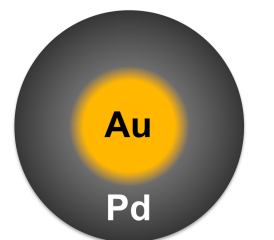

l' 0.00

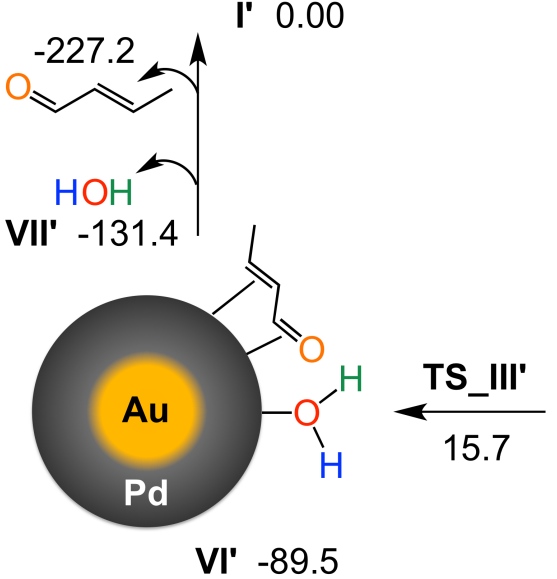

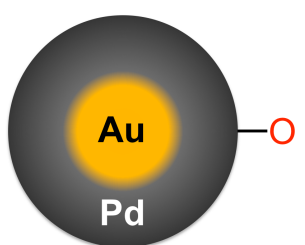

II' -5.3

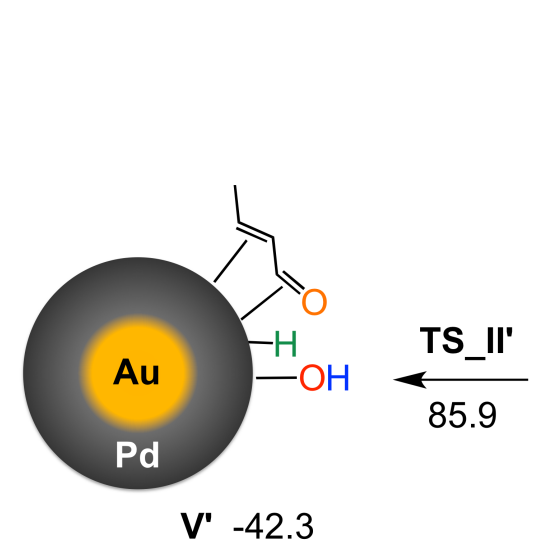

V' -42.3

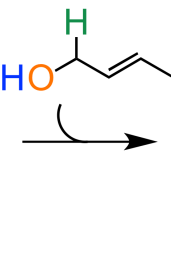

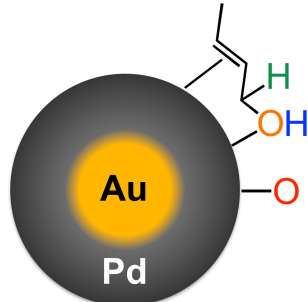

III' -21.7

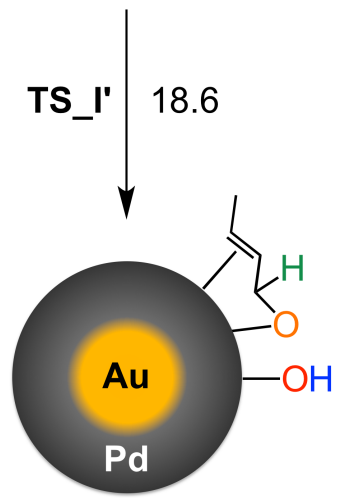

IV' 18.6

Scheme 3. Mechanism proposed for the heterogeneous PdAu-catalyzed oxidation of crotyl alcohol (relative free energies in $\mathrm{kJ} \mathrm{mol}^{-1}$ ).

The catalytic cycle starts with the activation of dioxygen on the PdAu nanoparticle l'; this process is known to proceed smoothly and thus the barrier for getting to II' has not been computed. ${ }^{22 a}$ This step is slightly exergonic and II' lies $5.3 \mathrm{~kJ} \mathrm{~mol}^{-1}$ below the separated starting reactants. A mechanism involving the peroxo species, such as the one invoked in the homogeneous mechanism or those proposed for gold-promoted systems, ${ }^{39}$ was ruled out because it has been stated that the $\mathrm{O}-\mathrm{O}$ bond is easily cleaved onto Pd surfaces. ${ }^{22 a}$ After that the crotyl alcohol is adsorbed onto the 
nanoparticle surface (III'); the binding of the substrate takes the energy $16.4 \mathrm{~kJ} \mathrm{~mol}^{-1}$ further down, indicating that a strong interaction is established between the palladium atoms and the double bond of the crotyl alcohol. In fact, the distance between the double bond and the palladium atoms on the surface is quite short and around $2.2 \AA$. The proton is then transferred from the alcohol group to the oxygen atom on the surface, through the low-lying transition state TS_l', with an energy requirement of around $40 \mathrm{~kJ} \mathrm{~mol}^{-1}$. Intermediate IV' lies at a very similar height than this transition state, indicating the deprotonation process should be reversible. The reaction proceeds, similarly to the homogeneous system, by the $\beta$-hydrogen elimination onto the palladium surface. The transition state governing this step (TS_II') is just $67.3 \mathrm{~kJ}$ $\mathrm{mol}^{-1}$ above IV' and produces intermediate V'. This species, where the final product is already formed, has the lowest potential energy so far $\left(-42.3 \mathrm{~kJ} \mathrm{~mol}^{-1}\right)$. Water is easily formed then by the recombination the hydrogen atom and hydroxide group on the surface ( $\mathbf{V I}$ '); this process requires $58 \mathrm{~kJ} \mathrm{~mol}^{-1}$ to jump over the corresponding transition state barrier TS_III'. An alternative pathway connecting IV' with VI' consists of the direct $\beta$-hydrogen transfer between the substrate and the hydroxyl group on the surface; however, the transition state found for this process lies higher than both TS_Il' and TS_II'. The final steps of the catalytic cycle correspond to the desorption of the products: water and crotonaldehyde. Both processes are energetically favored and liberate 41.9 and $95.8 \mathrm{~kJ} \mathrm{~mol}^{-1}$, respectively.

The overall heterogeneous reaction is exergonic by $227.2 \mathrm{~kJ} \mathrm{~mol}^{-1}$. The highest energy barrier is located, as in the homogeneous reaction, between III' and TS_II' i.e. between the coordination of the crotyl alcohol to the nanoparticle surface and the $\beta$-hydrogen transfer transition state. The height of the global reaction barrier is $105.6 \mathrm{~kJ} \mathrm{~mol}^{-1}$, thus indicating that the process should work at room temperature although it should not be expected to be extremely fast. This value is higher than the one computed for the homogeneous pathway $\left(87.8 \mathrm{~kJ} \mathrm{~mol}^{-1}\right)$; nevertheless, the heterogeneous catalyst is expected to be more robust and durable, therefore providing a better platform for crotyl alcohol oxidation.

3.3 Comparison and interplay between homogeneous and heterogeneous mechanisms

The computed relative free energy profiles for both homogeneous and heterogeneous catalytic cycles are shown in Scheme 4. As may be observed both reactions follow the same elementary steps with very similar energy requirements. As stated above the 
overall reaction barrier for both processes is found between the intermediates formed after the crotyl alcohol coordination to the palladium catalyst (III and III') and the corresponding $\beta$-H elimination transition states (TS_III and TS_II'). The main divergence between both catalytic cycles is found in the first steps: the dioxygen activation (II and II') and the substrate deprotonation (TS_II and TS_I'), probably due to the intrinsic structural differences between those species. Nevertheless, after the initial steps both profiles follow the same trend, indicating that the catalyst nature becomes less important.

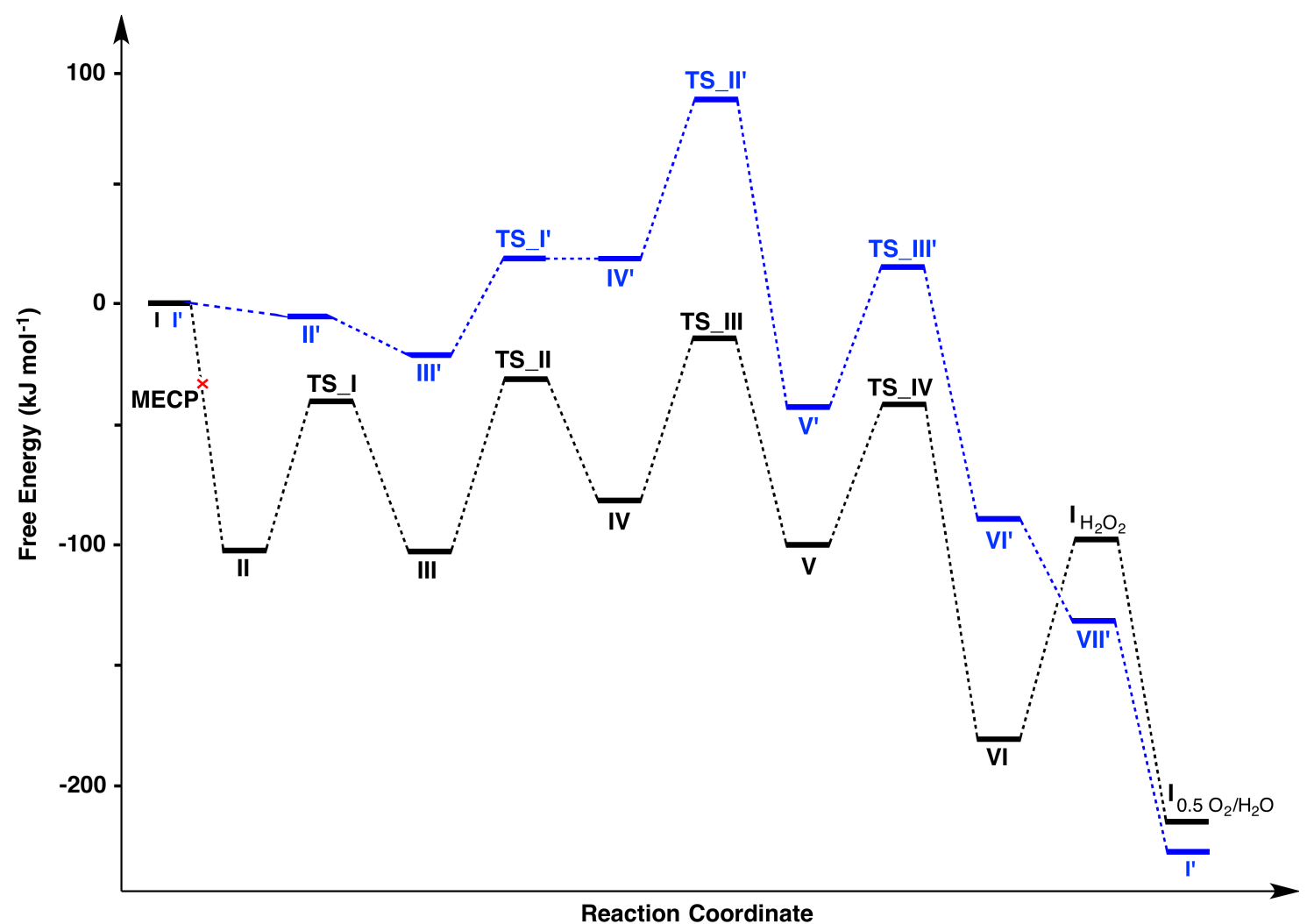

Scheme 4. Computed relative free energy profiles for the homogeneous (black) and heterogeneous (blue) reactions.

So far, both homogeneous and heterogeneous catalytic cycles have been treated separately and thus it is assumed that only one of the two mechanisms is operative during the reaction. However, the oxidation of crotyl alcohol has also been carried out successfully in an intermediate situation $i$. e. with $\mathrm{Au}$ nanoparticles and a $\mathrm{Pd}(\mathrm{II})$ salt, where both mechanisms could be working in parallel. Therefore it seems obvious that there should be a link connecting the homogeneous and heterogeneous catalytic 
pathways; leaching and deposition processes are the most plausible candidates to assume this role. This notion is not new and has been already proposed from a conceptual point of view for other reactions e.g. Heck coupling. ${ }^{40}$ However, the driving force responsible for the leaching processes and the stability of the heterogeneous systems under reaction conditions has never been quantified, not even computationally. For the alcohol oxidation reaction with the core-shell $\mathrm{PdAu}$ nanoparticles studied here the processes linking the homogeneous and heterogeneous worlds should be oxidative leaching and deposition after reduction to $\operatorname{Pd}(0)$ (Scheme $5)$.

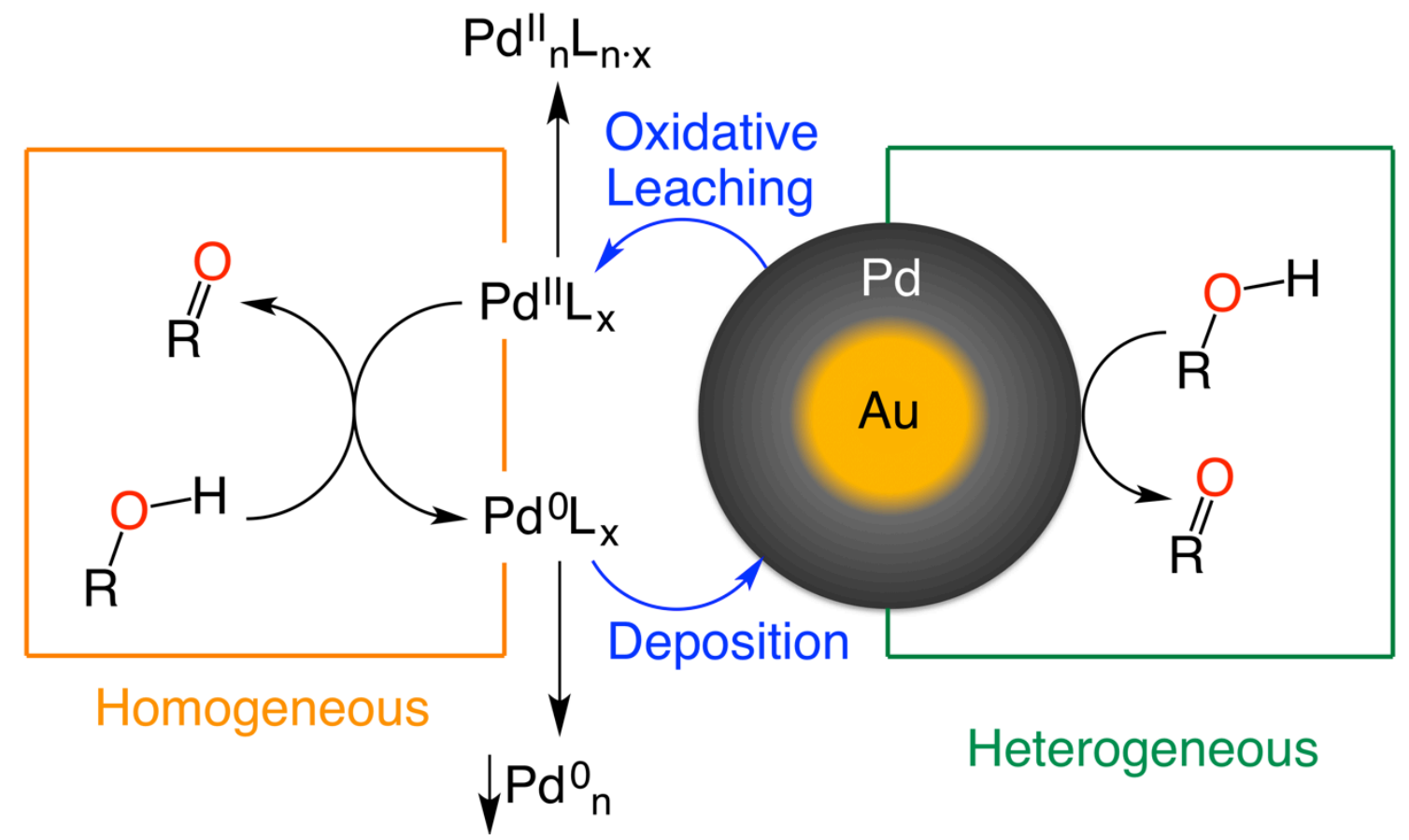

Scheme 5. Leaching/deposition link between homogeneous and heterogeneous mechanisms for alcohol oxidation with palladium catalysts.

Oxidative leaching may produce a mononuclear palladium(II) species able to oxidize the alcohol substrate; of course, this reaction requires an external oxidant present in the reaction mixture. In the case of the studied 3:1 PdAu nanoparticles the oxidatively leached complex could be the peroxopalladate II, which would be obtained from the nanoparticle surface in the presence of chloride ligands and dioxygen. The ability of this complex to react with crotyl alcohol for delivering the corresponding aldehyde has been shown above. After the reaction the palladium(0) complex $\mathbf{I}$ is formed again and can be deposited onto the nanoparticle, preventing the formation and precipitation of palladium black. The oxidative leaching process has been computed as a 
thermodynamic cycle (for a single palladium atom on an Au nanoparticle, Scheme 6 and Table 1). It has to be noted that the adsorption/desorption energy of $\mathrm{PdCl}_{2}$ is referred to a naked $\mathrm{Au}(111)$ surface, where the $\mathrm{Pd}$ atom has only three neighboring $\mathrm{Au}$ atoms. In the $\mathrm{PdCl}_{2}$ desorption from a complete $\mathrm{PdAu}$ nanoparticle, the interaction of the leaving $\mathrm{Pd}$ atom with the gold atoms would be lost as well as the interaction with the neighboring six $\mathrm{Pd}$ atoms. The cohesive energy term added to the thermodynamic cycle accounts for the energy required to eliminate the interaction between the leaving atom and its Pd neighbors; which corresponds to one half of the cohesive energy of Pd $\left(376 \mathrm{~kJ} \mathrm{~mol}^{-1}\right)$.

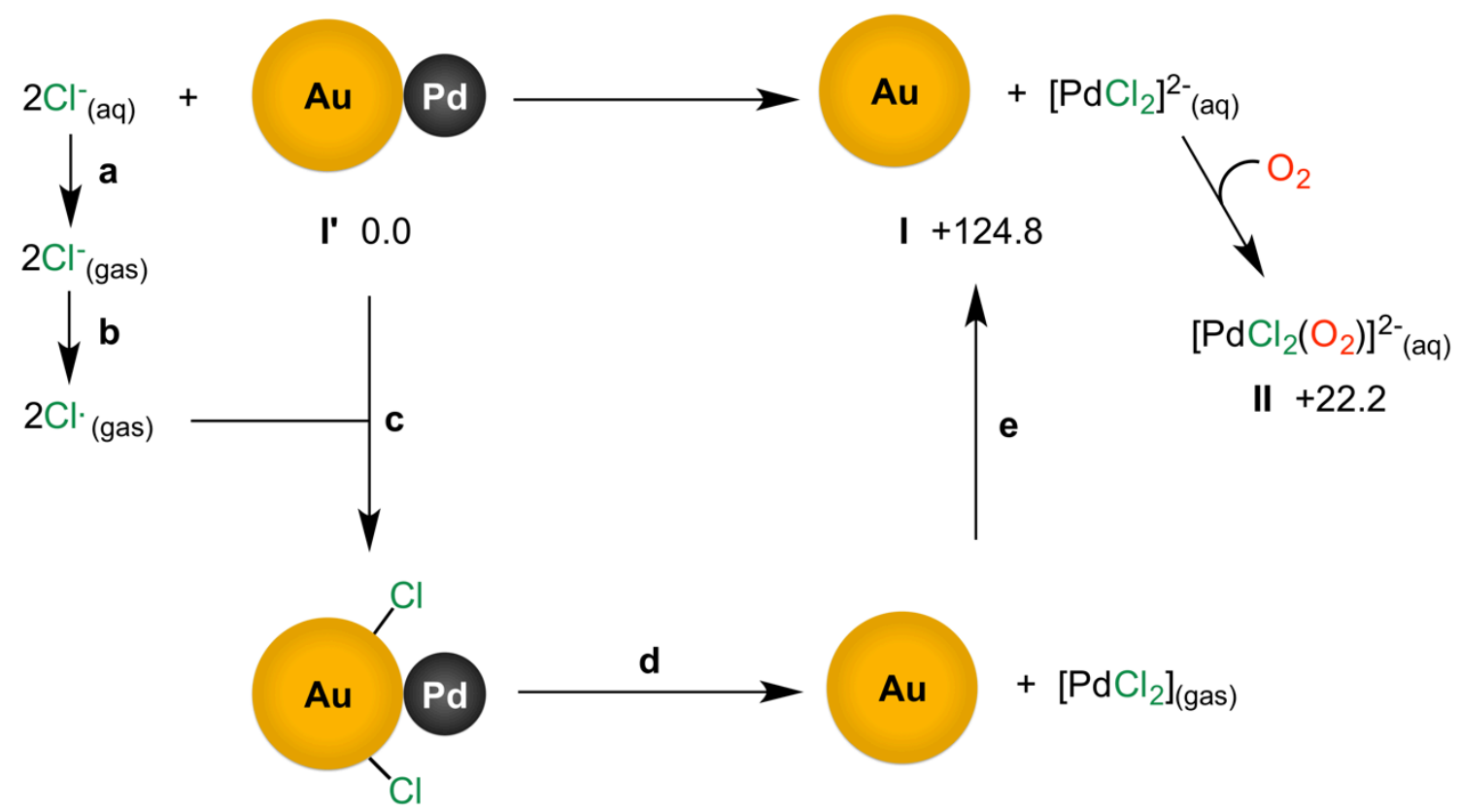

Scheme 6. Thermodynamic cycle employed to compute the relative energies for the oxidative leaching process (bold letters refer to the different steps described in Table 1 , relative energies in $\mathrm{kJ} \mathrm{mol}^{-1}$ ).

The calculations state that extracting $\left[\mathrm{PdCl}_{2}\right]^{2-}$ (I) from a PdAu nanoparticle is not an easy task because the process is endergonic by almost $125 \mathrm{~kJ} \mathrm{~mol}^{-1}$. However, if dioxygen is present (or coadsorbed) I could be readily oxidized into II, which is just slightly higher in energy than the starting system $\left(22.2 \mathrm{~kJ} \mathrm{~mol}^{-1}\right)$, and makes the oxidative leaching process possible, although unlikely. The computed thermodynamic driving force of the leaching process is a measure of the stability of the core-shell $\mathrm{PdAu}$ nanoparticle catalyst. Similar approaches based on the computation of very few 
stability terms (e.g. phase separation, segregation, etc.) are very common in heterogeneous catalysis and are routinely employed as filters when optimizing a catalyst. ${ }^{41}$ Additionally, other complex processes may take place on the surface of the catalyst, compromising the overall stability and performance in gas-solid reactions. An example of this is the dynamic formation of single atom catalytic sites from the bulk material, ${ }^{42}$ which clearly resembles the leaching mechanism described here.

Table 1. Computed energies employed to build the thermodynamic cycle describing the oxidative leaching process (energies in $\mathrm{kJ} \mathrm{mol}^{-1}$ ).

\begin{tabular}{|c|c|c|}
\hline Step & Energy & Process \\
\hline a & +539.8 & $\mathrm{Cl}_{(\text {(aq) }}^{-}$desolvation: $2 \mathrm{Cl}_{(\text {(aq) }}^{-} \rightarrow 2 \mathrm{Cl}_{\text {(gas) }}^{-}$ \\
\hline $\mathbf{b}$ & +714.0 & $\mathrm{Cl}^{-}{ }_{\text {(gas) }}$ oxidation (Electron Affinity): $2 \mathrm{Cl}^{-}{ }_{\text {(gas) }} \rightarrow 2 \mathrm{Cl}{ }_{\text {(gas) }}$ \\
\hline \multirow[t]{2}{*}{ c } & -457.3 & Chlorine atoms adsorption onto the nanoparticle \\
\hline & +91.3 & Entropy loss from $2 \mathrm{Cl}$ adsoprtion \\
\hline \multirow[t]{4}{*}{ d } & -103.6 & $\mathrm{PdCl}_{2 \text { (gas) }}$ formation onto the Au nanoparticle \\
\hline & +256.2 & $\mathrm{PdCl}_{2 \text { (gas) }}$ desorption \\
\hline & -51.6 & Entropy gain from $\mathrm{PdCl}_{2}$ desorption \\
\hline & +188.0 & Cohesive energy loss \\
\hline \multirow[t]{2}{*}{ e } & -497.9 & $\mathrm{PdCl}_{2}$ reduction: $\mathrm{PdCl}_{2 \text { (gas) }} \rightarrow\left[\mathrm{PdCl}_{2}\right]_{(\text {gas })}^{2-}$ \\
\hline & -554.1 & {$\left[\mathrm{PdCl}_{2}\right]^{2-}$ solvation: $\left[\mathrm{PdCl}_{2}\right]^{2-}{ }_{\text {(gas) }} \rightarrow\left[\mathrm{PdCl}_{2}\right]_{(\mathrm{aq})}^{2-}$} \\
\hline Total & +124.8 & \\
\hline
\end{tabular}

These calculations can help us putting together a complete energy profile containing both the computed homogeneous and heterogeneous pathways (Scheme 7). 


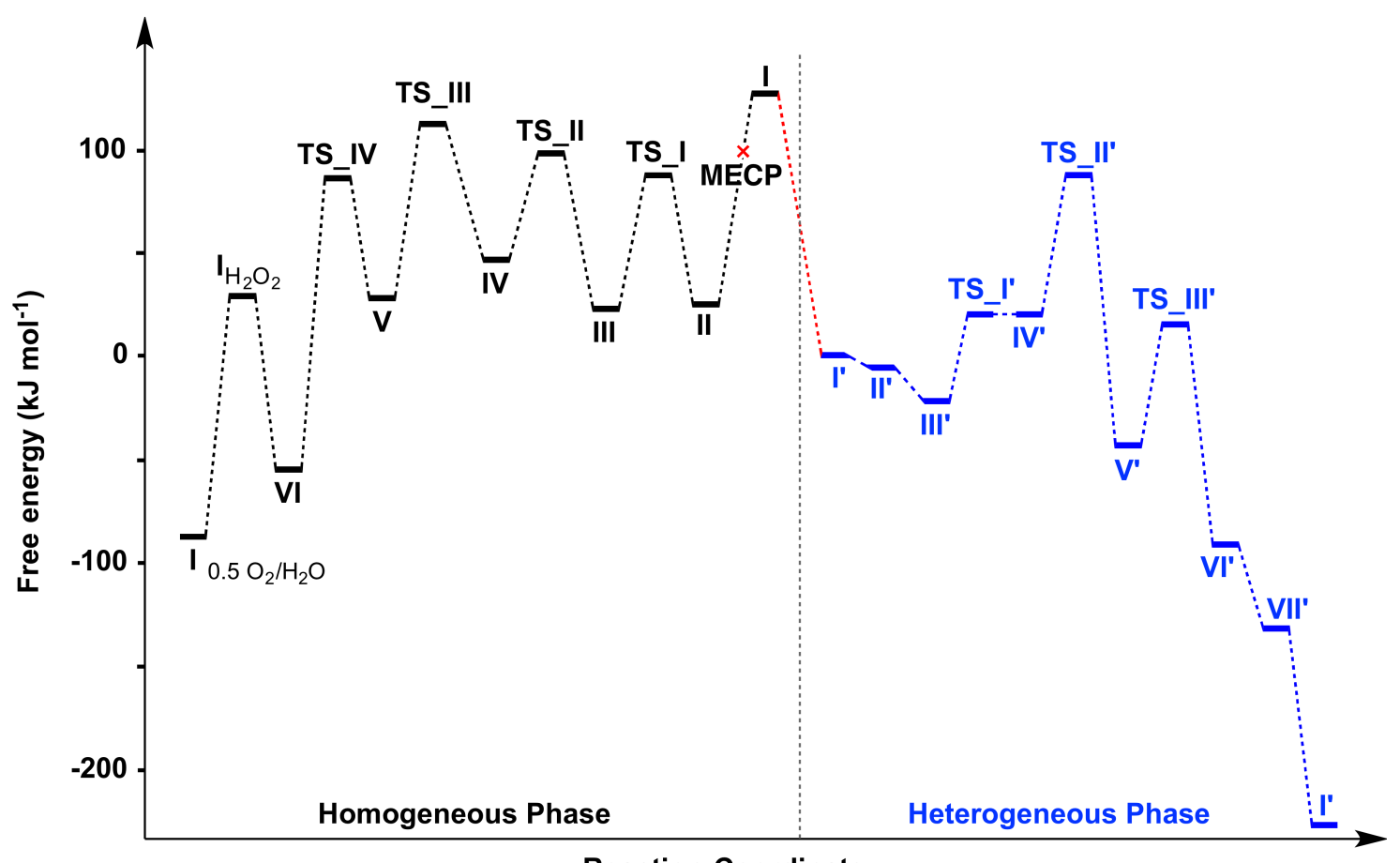

Reaction Coordinate

Scheme 7. Joint relative free energy profile (in $\mathrm{kJ} \mathrm{mol}^{-1}$ ) for the homogeneous (black) and heterogeneous (blue) pathways for crotyl alcohol oxidation.

As stated above, the oxidative leaching process (going from I' to II) seems to be quite unlikely. These results agree with the experimental observations under different reaction conditions. In the case of employing the core-shell 3:1 PdAu nanoparticles, the oxidative leaching process is not competitive and thus the reaction works entirely under the heterogeneous regime, which provides a good and stable platform for crotyl alcohol oxidation. When palladium(II) salts are used (e.g. $\mathrm{K}_{2} \mathrm{PdCl}_{2}$ ) the reaction shows a good performance but only for a limited time because of the formation of reduced $\mathrm{Pd}$ aggregates, which end up taking the active species out of the catalytic cycle. In the case of the mixed systems with $\mathrm{Pd}(\mathrm{II})$ salts and nanoparticles an intermediate situation is found, the homogeneous cycle may be operative for a while but, upon reduction, the palladium is adsorbed onto the nanoparticles giving rise to a completely functional heterogeneous system. This last situation entails the continuous deposition of $\mathrm{Pd}$ on the nanoparticles, making them larger over time as observed experimentally. The effect of the uncontrolled deposition may also affect the catalytic performance of the heterogeneous system since pure Pd nanoparticles are not active towards the crotyl alcohol oxidation (see below). 
Oxidative leaching can be favored or even induced by the presence of ligands, which could stabilize the oxidized palladium species. This can seriously hamper the overall performance of the reaction in cases where the oxidatively leached species turns out to be inactive. Some nice examples of this behavior have been recently presented and discussed by Lercher et al. ${ }^{5 b-d}$ in vinyl acetate monomer (VAM) synthesis reactions with PdAu nanoparticles. In those cases palladium(II) species are formed under the reaction conditions by oxidative leaching from PdAu nanoparticles. VAM synthesis is carried out by reacting ethylene $\left(\mathrm{C}_{2} \mathrm{H}_{4}\right)$ and acetic acid $(\mathrm{AcOH})$ under aerobic conditions; therefore, the strong interactions of acetic acid (and possibly acetate) with the palladium atoms in the nanoparticles allow the leaching palladium(II) acetate species $\left(\operatorname{Pd}_{n}(O A c)_{2 n}\right)$. The trimeric $\mathrm{Pd}_{3}(\mathrm{OAc})_{6}$ and dimeric $\mathrm{Pd}_{2}(\mathrm{OAc})_{4}$ complexes are postulated as the main leaching products; it has been stated that the equilibrium between these two compounds in $\mathrm{AcOH}$ favors the former. ${ }^{43}$ The computed free energies of these $\mathrm{Pd}_{n}(\mathrm{OAc})_{2 \mathrm{n}}$ complexes confirm that the trinuclear complex is the most stable since it lies more than $0.66 \mathrm{eV}$ lower than $\mathrm{Pd}_{2}(\mathrm{OAc})_{4}+\mathrm{Pd}(\mathrm{OAc})_{2}$. There is no evidence confirming the formation of the monomeric $\mathrm{Pd}(\mathrm{OAc})_{2}$ species, although the computed free energies indicate it should be very close to the dimeric species. $\operatorname{Pd}_{3}(O A c)_{6}$ turns out to be quite stable and, in principle, unreactive under the conditions applied in VAM synthesis. Thus, the formation of this trimeric form difficulties the overall reaction performance and contributes to the depletion of the active catalyst. A plausible solution to this problem consists of the addition of MOAc promoters $(\mathrm{M}=\mathrm{K}, \mathrm{Cs})$ that can react with $\mathrm{Pd}_{3}(\mathrm{OAc})_{6}$, to form the catalytically active $\mathrm{M}_{2} \mathrm{Pd}_{2}(\mathrm{OAc})_{6}$ species, ${ }^{44}$ which, in turn, is able to catalyze the VAM synthesis reaction. The effect of the coadsorbed ligands on the catalyst surface has also been computationally studied for the palladium leaching under $\mathrm{CO}$ atmosphere from pure $\mathrm{Pd}$ ensembles. The loss of the surface palladium atoms, is enhanced by the formation of $P d$ subcarbonyl species $\left[\operatorname{Pd}(C O)_{x}\right](x=2,3)$, which become thermodynamically favorable at high CO coverage. ${ }^{45}$ Thus, oxidative leaching and deposition processes may be beneficial under certain conditions. conditions, producing reactive species that can catalyze the desired reactions. On the other hand, new deactivation pathways open from the leached species, by the aggregation of either the oxidized or the reduced species i.e. formation of bulk metal nanoparticles.

The formation of successive $\mathrm{Pd}$ layers on the surface of the core-shell $\mathrm{PdAu}$ nanoparticles is another drawback that can lead to inactivation of the catalytic species. Scott et al. have observed experimentally that pure Pd nanoparticles are not active towards crotyl alcohol oxidation. ${ }^{11 \mathrm{e}}$ The core-shell PdAu nanoparticles are not affected 
by this because the palladium atoms remain attached to the surface throughout the whole reaction. On the other hand, the $\mathrm{K}_{2} \mathrm{PdCl}_{4} / \mathrm{Au} \mathrm{NP}$ catalytic systems, where the palladium is deposited on the surface after the first turnover, may produce thicker palladium layers that could inactivate the catalyst in the long term. ${ }^{46}$ The difference in electronegativities between gold and palladium ( 2.54 vs. 2.20 , respectively) provides a plausible explanation for this behavior. $\mathrm{Au}$ is more electronegative and thus enhances the activity of the reaction by decreasing the d-electron density of the nearby Pd atoms i.e. makes them more easily oxidized. If the nanoparticles grow by adding successive palladium layers this effect fades and ultimately leads to the poor performance observed for pure Pd ensembles. The deposition energy of a palladium atom on the surface of a gold nanoparticle covered with a monolayer of $\mathrm{Pd}$ has been calculated following the same thermodynamic cycle as above (Scheme 8, see data in the SI). As may be observed the addition of an extra $\mathrm{Pd}$ atom in the second layer takes the energy $139.1 \mathrm{~kJ} \mathrm{~mol}^{-1}$ further down, confirming that subsequent palladium layers may be formed onto the existing nanoparticles under the reaction conditions.

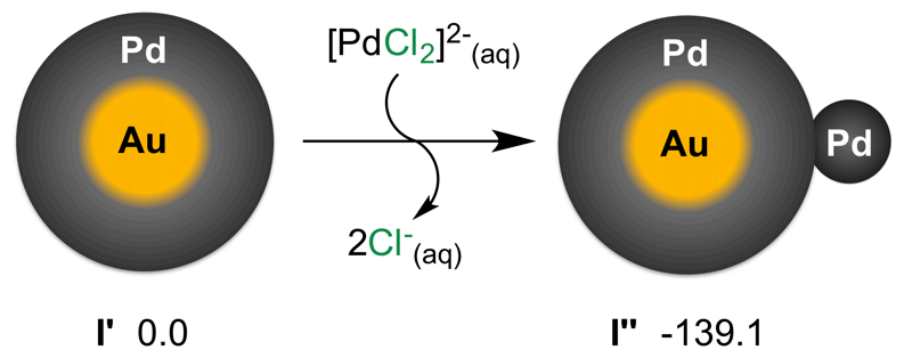

Scheme 8. Deposition of a second Pd layer onto a PdAu nanoparticle (relative free energies in $\mathrm{kJ} \mathrm{mol}^{-1}$ ).

\section{CONCLUSIONS}

We have computationally studied the palladium-catalyzed oxidation of crotyl alcohol to crotonaldehyde with two different homogeneous $\left(\mathrm{K}_{2} \mathrm{PdCl}_{4}\right)$ and heterogeneous (coreshell 3:1 PdAu nanoparticles) systems. The favored mechanisms for both reactions are very similar, comprise essentially the same elementary steps and have practically equal energy requirements. The highest barrier for both catalytic cycles is located between the crotyl alcohol adsorption on the palladium catalyst and the $\beta$ hydride/hydrogen elimination transition state, which needs 87.8 and $105.5 \mathrm{~kJ} \mathrm{~mol}^{-1}$ for the homogeneous and heterogeneous systems, respectively. With these values at 
hand it seems that both catalysts should work, with the former showing a better performance towards crotyl alcohol oxidation. However, the homogeneous reaction suffers from poor stability and tendency to produce Pd-black from transient palladium $(0)$ species, such as the catalytically active $\left[\mathrm{PdCl}_{2}\right]^{2-}$. On the other hand, the purely heterogeneous system is more robust and durable, and provides a suitable catalytic cycle for alcohol oxidation.

Both catalytic systems can be connected through the oxidative leaching and deposition processes, which can be computationally constructed. In the case studied it seems that the oxidative leaching may be possible but, in the end, it is not able to balance the competition between the homogeneous and heterogeneous pathways, which ends up favoring the latter. The calculations also ascertain that $\operatorname{Pd}(0)$ deposition is favored onto $\mathrm{Au}$ and PdAu nanoparticles. Thus, the nanoparticles are likely to grow by adding subsequent reduced palladium layers, as observed experimentally. To the best of our knowledge, this work constitutes the first example of how computational homogeneous and heterogeneous pathways can be sewn together into a single unit, allowing the interpretation of the interplay between both worlds under the same conditions.

\section{SUPPORTING INFORMATION}

Absolute free energies, secondary homogeneous cycle, other thermodynamic cycles constructed and results obtained with the B3LYP functional. This material is available free of charge via the Internet at http://pubs.acs.org. The optimized structures can be found in the ioChem-BD repository (10.19061/iochem-bd-1-6).

\section{ACKNOWLEDGMENTS}

This research has been supported by the MINECO (CTQ2015-68770-R). We also acknowledge BSC-CNS for providing generous computational resources.

\section{REFERENCES}

(1) a) Somorjai, G. A.; McCrea, K. Appl. Catal., A 2001, 222 ,3-18. b) Somorjai, G. A.; Contreras, A. M.; Montano, M.; Rioux, R. M. Proc. Natl. Acad. Sci. U. S. A. 2006, 103, 10577-10583.

(2) Chadwick, J. C.; Duchateau, R.; Freixa, Z.; van Leeuwen, P. W. N. M. Homogeneous Catalysts: Activity - Stability - Deactivation; Wiley-VCH: Weinheim, 2011.

(3) a) Astruc, D.; Lu, F.; Aranzaes, J. R. Angew. Chem., Int. Ed. 2005, 44, 7852-7872.

b) Crabtree, R. H. Chem. Rev. 2012, 112, 1536-1554. 
(4) a) García-Mota, M; Cabello, N.; Maseras, F.; Echavarren, A. M.; Pérez-Ramírez, J.; López, N. ChemPhysChem 2008, 9, 1624-1629. B) Plata, J.J.; García-Mota, M.; Braga, A.A.C.; López, N.; Maseras, F. J. Phys. Chem. A 2009, 113, 1758-11762.

(5) a) Witham, C. A.; Huang, W.; Tsung, C.-K.; Kuhn, J. N.; Somorjai, G. A.; Toste, F. D. Nat. Chem. 2010, 2, 36-41. b) Simson, S.; Jentys, A.; Lercher, J. A. J. Phys. Chem. C 2013, 117, 8161-8169. c) Hanrieder, E. K.; Jentys, A.; Lercher, J. A. ACS Catal. 2015, 5, 5776-5786. c) Hanrieder, E. K.; Jentys. A.; Lercher, J. A. J. Catal. 2016, 333, 71-77.

(6) a) Gross, E.; Liu, J. H.-C.; Toste, F. D.; Somorjai, G. A. Nat. Chem. 2012, 4, 947952. b) Wang, C.; Ciganda, R.; Salmon, L.; Gregurec, D.; Irigoyen, J.; Moya, S.; Ruiz, J.; Astruc, D. Angew. Chem. Int. Ed. 2016, 55, 3091-3095.

(7) Esfandiari, N. M.; Blum, S. A. J. Am. Chem. Soc. 2011, 133, 18145-18147.

(8) Silva, T. A. G.; Teixeira-Neto, E.; López, N; Rossi, L. M. Sci. Rep. 2014, 4, 5766.

(9) a) Stacchiola, D.; Calaza, F.; Burkholder, L.; Schwabacher, A. W.; Neurock, M.; Tysoe, W. T. Angew. Chem. 2005, 44, 4572-4574. b) Chen, M. S.; Kumar, D.; Yi, C. W.; Goodman, D. W. Science 2005, 310, 291-293. c) Han, P. S.; Axnanda, S.; Lyubinetsky, I.; Goodman, D. W. J. Am. Chem. Soc. 2007, 129, 14355-14361. d) Kumar, D.; Chen, M. S.; Goodman, D. W. Catal. Today 2007, 123, 77-85. e) GarciaMota, M.; Lopez, N. J. Am. Chem. Soc. 2008, 130, 14406-14407. f) Mazzone, G.; Rivalta, I.; Russo, N.; Sicilia, E. Chem. Commun. 2009, 14, 1852-1854. g) Calaza, F., Li, Z., Garvey, M., Neurock, M., Tysoe, W.T. Catal. Lett. 2013, 143, 756-762. h) Calaza, F., Mahapatra, M., Neurock, M., Tysoe, W.T. J. Catal. 2014, 312, 37-45.

(10) Edwards, J. K.; Solsona, B.; Ntainjua N., E.; Carley, A. F.; Herzing, A. A.; Kiely, C. J.; Hutchings, G. J. Science 2009, 323, 1037-1041.

(11) a) Enache, D. I.; Edwards, J. K.; Landon, P.; Solsona-Espriu, B.; Carley, A. F.; Herzing, A. A.; Watanabe, M.; Kiely, C. J.; Knight, D. W.; Hutchings, G. J. Science 2006, 311, 362-365. b) Hou, W.; Dehm, N. A.; Scott, R. W. J. J. Catal. 2008, 253, 22-27. c) Lee, A. F.; Hackett, S. F. J.; Hutchings, G. J.; Lizzit, S.; Naughton, J.; Wilson, K. Catal. Today 2009, 145, 251-257. d) Wang, D.; Villa, A.; Spontoni, P.; Su, D. S.; Prati, L. Chem.-Eur. J. 2010, 16, 10007-10013. e) Balcha, T.; Strobl, J.; Fowler, C.; Dash, P.; Scott, R. W. J. ACS Catal. 2011, 1, 425-436. f) Nishimura, S.; Yakita, Y.; Katayama, M.; Higashimine, K.; Ebitani, K. Catal. Sci. Technol. 2013, 3, 351-359. g) Maclennan, A.; Banerjee, A.; Hu, Y.; Miller, J. T.; Scott, R. W. J. ACS Catal. 2013, 3, 1411-1419. h) Zhao, Z.; Arentz, J.; Pretzer, L. A.; Limpornpipat, P.; Clomburg, J. M.; Gonzalez, R.; Schweitzer, N. M.; Wu, T.; Millere, J. T.; Wong, M. S. Chem. Sci. 2014, 5, 3715-3728. i) Chang, C.-R.; Long, B.; Yang, X.-F.; Li, J. J. Phys. Chem. C 2015, 119, 16072-16081.

(12) Kesavan, L.; Tiruvalam, R.; Ab Rahim, M. H.; bin Saiman, M. I.; Enache, D. I.: Jenkins, R. L.; Dimitratos, N.; Lopez-Sanchez, J. A.; Taylor, S. H.; Knight, D. W.; Kiely, C. J.; Hutchings, G. J. Science 2011, 331, 195-199.

(13) Schwartz, J. T.; Lyman, S. D.; Motagamwala, A. H.; Mellmer, M. A.; Dumesic, J. A. ACS Catal. 2016, 6, 2047-2054.

(14) a) Chen, H.; Li, Y.; Zhang, F.; Zhang, G.; Fan, X. J.Mater.Chem. 2011, 21, 1765817661. b) Paalanen, P.; Weckhuysen, B. M.; Sankar, M. Catal. Sci. Technol. 2013, 3, 2869-2880.

(15) Maroun, F.; Ozanam, F.; Magnussen, O. M.; Behm, R. J. Science 2001, 293, 1811-1814.

(16) a) Soto-Verdugo, V.; Metiu, H. Surf. Sci. 2007, 601, 5332-5339. b) García-Mota, M.; López, N. Phys. Rev. B 2010, 82, 075411.

(17) Huang, Y.; Zhou, X.; Yin, M.; Liu, C.; Xing, W. Chem. Mater. 2010, 22, 5122-5128.

(18) Lucci, F. R.; Darby, M. T.; Mattera, M. F. G.; Ivimey, C. J.; Therrien, A. J.; Michaelides, A.; Stamatakis, M.; Sykes, E. C. H. J. Phys. Chem. Lett. 2016, 7, 480-485.

(19) Andersin, J., Parkkinen, P., Honkala, K. J. Catal. 2012, 290, 118-125. 
(20) a) Zaw, K.; Lautens, M.; Henry, P. M. Organometallics 1983, 2, 197-199. b) Bäckvall, J.-E. Acc. Chem. Res. 1983, 16, 335-342.

(21) Schultz, M. J.; Adler, R. S.; Zierkiewicz, W.; Privalov, T.; Sigman, M. S. J. Am. Chem. Soc. 2005, 127, 8499-8507.

(22) a) García-Mota, M.; López, N. Phys. Chem. Chem. Phys. 2011, 13, 5790-5797. b) Kwon, Y.; Lai, S. C. S.; Rodriguez, P.; Koper, M. T. M. J. Am. Chem. Soc. 2011, 133, 6914-6917.

(23) Frisch, M. J.; Trucks, G. W.; Schlegel, H. B.; Scuseria, G. E.; Robb, M. A.; Cheeseman, J. R.; Scalmani, G.; Barone, V.; Mennucci, B.; Petersson, G. A.; Nakatsuji, H.; Caricato, M.; Li, X.; Hratchian, H. P.; Izmaylov, A. F.; Bloino, J.; Zheng, G.; Sonnenberg, J. L.; Hada, M.; Ehara, M.; Toyota, K.; Fukuda, R.; Hasegawa, J.; Ishida, M.; Nakajima, T.; Honda, Y.; Kitao, O.; Nakai, H.; Vreven, T.; Montgomery, J., J. A.; Peralta, J. E.; Ogliaro, F.; Bearpark, M.; Heyd, J. J.; Brothers, E.; Kudin, K. N.; Staroverov, V. N.; Kobayashi, R.; Normand, J.; Raghavachari, K.; Rendell, A.; Burant, J. C.; lyengar, S. S.; Tomasi, J.; Cossi, M.; Rega, N.; Millam, N. J.; Klene, M.; Knox, J. E.; Cross, J. B.; Bakken, V.; Adamo, C.; Jaramillo, J.; Gomperts, R.; Stratmann, R. E.; Yazyev, O.; Austin, A. J.; Cammi, R.; Pomelli, C.; Ochterski, J. W.; Martin, R. L.; Morokuma, K.; Zakrzewski, V. G.; Voth, G. A.; Salvador, P.; Dannenberg, J. J.; Dapprich, S.; Daniels, A. D.; Farkas, Ö.; Foresman, J. B.; Ortiz, J. V.; Cioslowski, J. F., D. J. Gaussian09, Revision B.01, Gaussian, Inc.: Wallingford CT, 2009.

(24) a) Perdew, J. P.; Burke, K.; Ernzerhof, M. Phys. Rev. Lett. 1996, 77, 3865-3868.

b) Perdew, J. P.; Burke, K.; Ernzerhof, M. Phys. Rev. Lett. 1997, 78, 1396.

(25) a) Becke, A. D. J. Chem. Phys. 1993, 98, 5648-5652. b) Lee, C.; Yang, W.; Parr, R. G. Phys. Rev. B 1988, 37, 785-89; c) Miehlich, B.; Savin, A.; Stoll, H.; Preuss, H. Chem. Phys. Lett. 1989, 157, 200-206.

(26) a) Ditchfield, R.; Hehre, W. J.; Pople, J. A. J. Chem. Phys. 1971, 54, 724-728. b) Hehre, W. J.; Ditchfield, R.; Pople, J. A. J. Chem. Phys. 1972, 56, 2257-2261. c) Hariharan, P. C.; Pople, J. A. Theor. Chem. Acc. 1973, 28, 213-222. d) Clark, T.; Chandrasekhar, J.; Spitznagel, G. W.; Schleyer, P. V. R. J. Comp. Chem. 1983, 294301. e) Frisch, M. J.; Pople, J. A.; Binkley, J. S. J. Chem. Phys. 1984, 80, 3265-3269.

(27) During the revision process, one of the reviewers indicated that the usage of the 6$31+G(d)$ basis set may introduce strong BSSE. Since most of the reaction steps are treated as substitution reactions the BSSE should be negligible. Nevertheless, the BSSE (if present) should fade away when the calculations are repeated with larger basis sets and thus the relative energy values along the reaction profile should change as the basis sets are increased. Using the $6-311+G^{* *}$ or aug-cc-pvtz basis sets for $\mathrm{C}, \mathrm{O}, \mathrm{Cl}$ and $\mathrm{H}$, while keeping the SDD basis set for $\mathrm{Pd}$, did not produce any significant difference (always below $2 \mathrm{~kJ} \mathrm{~mol}^{-1}$ ) in the free energy computed for the first three steps of the homogeneous catalytic cycle and therefore we believe our calculations are free of BSSE.

(28) a) Dunning, T. H.; Hay, P. J., In Modern Theoretical Chemistry, Schaefer III, H. F., Ed. Plenum: New York, 1976; Vol. 3, pp 1-28. b) Bergner, A.; Dolg, M.; Küchle, W.; Stoll, H.; Preuss, H. Mol. Phys. 1993, 80, 1431-1441.

(29) a) Tannor, D. J.; Marten, B.; Murphy, R.; Friesner, R. A.; Sitkoff, D.; Nicholls, A.; Honig, B.; Ringnalda, M.; Goddard, W. A. J. Am. Chem. Soc. 1994, 116, 1187511882. b) Marten, B.; Kim, K.; Cortis, C.; Friesner, R. A.; Murphy, R. B.; Ringnalda, M. N.; Sitkoff, D.; Honig, B. J. Phys. Chem. 1996, 100, 11775-11788.

(30) Marenich, A. V.; Cramer, C. J.; Truhlar, D. G. J. Phys. Chem. B 2009, 113, 63786396.

(31) Harvey, J. N.; Aschi, M.; Schwarz, H.; Koch, W. Theor. Chem. Acc. 1998, 99, 9599.

(32) Kresse, G.; Joubert, D. Phys. Rev. B 1999, 59, 1758-1775.

(33) a) Kresse, G.; Furthmuller, J. Comput. Mater. Sci. 1996, 6, 15-50. b) Kresse, G.;

Furthmuller, J. Phys. Rev. B 1996, 54, 11169-11186.

(34) Monkhorst, H. J.; Pack, J. D. Phys. Rev. B 1976, 13, 5188-5192. 
(35) Henkelman, G.; Uberuaga, B. P.; Jonsson, H. J. Chem. Phys. 2000, 113, 9901-9904.

(36) Garcia-Ratés, M.; López, N. J. Chem. Theory Comput. 2016, 12, 1331-1341.

(37) a) Mutule, I.; Joo, B.; Medne, Z.; Kalnins, T.; Vedejs, E.; Suna, E. J. Org. Chem. 2015, 80, 3058-3066. b) Stahl, S. S.; Thorman, J. L.; Nelson, R. C.; Kozee, M. A. J. Am. Chem. Soc. 2001, 123, 7188-7189.

(38) Popp, B. V.; Wendlandt, J. E.; Landis, C. R.; Stahl, S. S. Angew. Chem., Int. Ed. 2007, 46, 601-604.

(39) a) Bongiorno, A.; Landman, U. Phys. Rev. Lett. 2005, 95, 106102. b) Chang, C.R.; Yang, X.-F.; Long, B.; Li, J. ACS Catal. 2013, 3, 1693-1699. c) Saavedra, J.; Doan, H. A.; Pursell, C. J.; Grabow, L. C.; Chandler, B. D. Science, 2014, 1599-1602. d) Chang, C.-R.; Huang, Z.-Q.; Li, J. Nano Res. 2015, 8, 3737-3748.

(40) Köhler, K.; Kleist, W.; Pröckl, S. S. Inorg. Chem. 2007, 46, 1876-1883.

(41) Nørskov, J. K.; Bligaard, T.; Rossmeisl, J.; Christensen, C. H. Nat. Chem. 2009, 1, 37-46.

(42) Wang, Y.-G.; Mei, D.; Glezakou, V.-A.; Li, J.; Rousseau, R. Nat. Comm. 2015, 6, 6511.

(43) Stoyanov, E. J. Struct. Chem. 2000, 41, 440-445.

(44) Winstein, S.; McCaskie, J.; Lee, H.-B.; Henry, P. M. J. Am. Chem. Soc. 1976, 98, 6913-6918.

(45) Chang, C.-R-; Zhao, Z.-J.; Köhler, K.; Genest, A.; Li, J.; Rösch, N. Catal. Sci. Technol. 2012, 2, 2238-2248.

(46) Ouyang, R.; Liu, J.-X.; Li, W.-X. J. Am. Chem. Soc. 2013, 135, 1760-1771. 
For Table of Contents Only

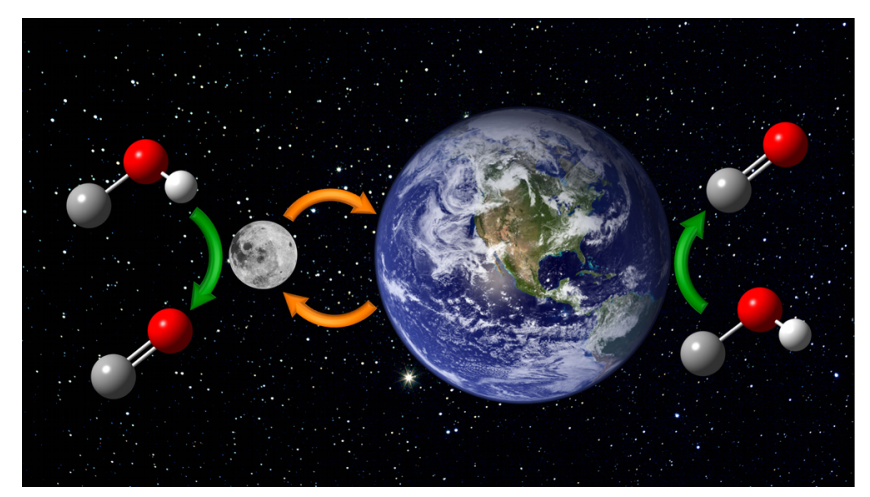

